\title{
O INTELECTUAL ORGÂNICO E A CONSTRUÇÃO DA VONTADE COLETIVA DA CLASSE SUBALTERNA NA DIREÇÃO DA FORMAÇÃO HUMANA
}

\author{
INTELECTUAL ORGÁNICO Y LA CONSTRUCCIÓN DE LA VOLUNTAD \\ COLECTIVA DE LA CLASE SUBALTERNA EN SINTONÍA CON LA FORMACIÓN \\ HUMANA
}

ORGANIC INTELLECTUAL AND THE CONSTRUCTION OF THE COLLECTIVE WILL OF THE SUBALTERNAL CLASS IN TUNE WITH HUMAN FORMATION

\author{
Pedro Pereira dos SANTOS ${ }^{1}$ \\ Escolástica SANTOS ${ }^{2}$ \\ Daniele Kelly Lima OLIVEIRA ${ }^{3}$
}

RESUMO: Este trabalho de procedimento bibliográfico, fundamenta-se na perspectiva gramsciana e visa refletir sobre o conceito de intelectual orgânico e a construção da vontade coletiva em sintonia com a formação humana, que é um processo de desenvolvimento de múltiplas dimensões do sujeito histórico e que requer a articulação dialética entre os fatores objetivos e subjetivos. O estudo demonstra que a atividade do intelectual orgânico da classe subalterna tem dupla dimensão: a desconstrução da hegemonia dominante e a construção de uma nova hegemonia comprometida com a formação humana. Revela também que o conhecimento comprometido com a emancipação humana precisa ser apropriado e incorporado pelos sujeitos históricos a fim de se modificar e transformar o mundo.

PALAVRAS-CHAVE: Intelectual orgânico. Vontade coletiva. Formação humana.

RESUMEN: Este trabajo de procedimiento bibliográfico se basa en la perspectiva Gramsciana y tiene como objetivo reflexionar sobre el concepto de intelectual orgánico y la construcción de la voluntad colectiva en línea con la formación humana, que es un proceso de desarrollo de múltiples dimensiones del sujeto histórico que requiere una articulación dialéctica entre factores objetivos y subjetivos. El estudio muestra que la actividad del intelectual orgánico de la clase subalterna tiene una doble dimensión: la deconstrucción de la hegemonía dominante y la construcción de una nueva hegemonía comprometida con la

${ }^{1}$ Universidade Federal do Piauí (UFPI), Teresina - PI - Brasil. Professor Adjunto no Departamento de Fundamentos da Educação (DEFE) e Líder do Núcleo de Estudos e Pesquisas em Educação e Emancipação Humana (NESPEM/UFPI). Doutorado em Educação (UFC). ORCID: http://orcid.org/0000-0003-0312-0000. Email: santos. pedropereira@gmail.com

${ }^{2}$ Universidade Federal do Piaú (UFPI), Teresina - PI - Brasil. Professora Adjunta no Departamento de Fundamentos da Educação (DEFE) e Líder do Núcleo de Estudos e Pesquisas em Educação e Emancipação Humana (NESPEM/UFPI). Doutorado em Educação (UFC). ORCID: https://orcid.org/0000-0002-3407-9496. Email: escol.santos@ufpi.edu.br

${ }^{3}$ Universidade Estadual do Vale do Acaraú (UVA), Sobral - CE - Brasil. Professora Adjunta no Curso de Pedagogia e Coordenadora do Grupo de Pesquisas e Estudos Educação, Movimentos sociais, Políticas Públicas e Diversidade (GPEEMPODERAR/UVA). Doutora em Educação (UFC). ORCID: https://orcid.org/0000-00028891-7328. E-mail: dankel28@yahoo.com.br 
formación humana. También revela que el conocimiento comprometido con la emancipación humana necesita ser apropiado e incorporado por los sujetos históricos para modificar y transformar el mundo.

PALABRAS CLAVE: Intelectual orgánico. Voluntad colectiva. Formación humana.

ABSTRACT: This work of bibliographical procedure, is based on the Gramscian perspective and aims to reflect on the concept of organic intellectual and the construction of collective will in line with human formation, which is a process of development of multiple dimensions of the historical subject and which requires the dialectical articulation between objective and subjective factors. The study shows that the activity of the organic intellectual of the subaltern class has a double dimension: the deconstruction of the dominant hegemony and the construction of a new hegemony committed to human formation. It also reveals that knowledge committed to human emancipation needs to be appropriated and incorporated by historical subjects in order to change and transform the world.

KEYWORDS: Organic intellectual. Collective will. Human formation.

\section{Introdução}

Esta reflexão surge num contexto histórico marcado fortemente pelo avanço das forças de extrema direita, que ameaçam, sobretudo, a liberdade de expressão dos professores em sala de aula, conforme evidenciam as tentativas de aprovação do programa Escola sem Partido, doravante EsP.

Esse programa foi criado pelo Advogado Miguel Nagib em 2004 e transformado em projeto de lei por solicitação do deputado estadual do Rio de Janeiro, Flávio Bolsonaro, do Partido Social Cristão (PSC - RJ), que o apresentou em 13 de maio de 2014. Em seguida, o irmão do deputado, o vereador Carlos Bolsonaro (PSC - RJ), também o apresentou na Câmara Municipal-RJ.

Na tentativa de aprovação do EsP como parte das diretrizes da educação nacional, foram apresentados mais dois projetos de lei: um tramitou na Câmera dos Deputados (PL n ${ }^{\circ}$ 867/2015), do parlamentar Izalci Lucas, do Partido da Social Democracia Brasileira (PSDB) e outro no Senado (PL nº 193/2016), do senador Magno Malta, do Partido Republicano (PR ES).

Os projetos de lei que visam instituir o EsP em todos os níveis da educação brasileira objetivam, sobretudo, silenciar os professores, que com isso são impedidos de problematizar, em sala de aula, sobre um conjunto de temas, como gênero, sexualidade, feminismo, machismo, desigualdade social, lutas de classes, dentre outros. 
A negação da liberdade de expressão do docente manifesta-se de forma explícita no parágrafo IV, inciso III do PL (nº 867/2015), que afirma existir nas escolas um processo de doutrinação político-partidária dos estudantes, realizado pelo professor, que pretende formálos como militantes políticos, motivando-os "a participar de manifestações, atos públicos e passeatas".

O EsP - mesmo num país como o Brasil, marcado pela extrema desigualdade social ${ }^{4}-$ preconiza o mutismo do professor. Assim, este não pode problematizar as mazelas de ordem econômica, política, social e cultural e nem fazer críticas às convicções morais e religiosas, pois poderá ser denunciado como doutrinador pelas famílias e pelos estudantes que discordam da sua análise. Deste modo, depreende-se que os defensores do EsP separam o ato de educar do ato de instruir. Em sua perspectiva, educar seria uma tarefa da família e da igreja, enquanto os professores devem apenas transmitir conceitos dos livros didáticos sem relacioná-los aos problemas do contexto dos estudantes.

Assim, elege-se um professor que é refém das concepções individuais das famílias e dos estudantes, cuja visão de mundo, muitas vezes, reproduz conteúdos que validam o projeto societário burguês que se sustenta na contradição fundamental capital-trabalho. Isso põe em detrimento o professor como um intelectual que capta e reelabora criticamente o senso comum.

Na contracorrente do EsP, que reduz a função de professor a tarefeiro da sociabilidade burguesa, é que refletiremos sobre o conceito de intelectual orgânico e sua tarefa no processo de construção da vontade coletiva num contexto de aprofundamento da crise estrutural do capital e da pandemia da COVID-19.

\section{O conceito de intelectual como unidade do diverso}

O conceito de intelectual em Gramsci (2005, p. 84) é bastante amplo, como ele mesmo reconhece em uma carta escrita na prisão em 7 de setembro de 1931, afirmando que:

[...] amplio muito a noção de intelectual e não me limito à noção corrente, que se refere aos grandes intelectuais. Este estudo também leva a certas determinações do conceito de Estado, que, habitualmente, é entendido como sociedade política (ou ditadura, ou aparelho coercitivo, para moldar a massa popular segundo o tipo de produção e a economia de um dado momento), e

${ }^{4}$ Um estudo realizado em 2018 pelo Instituto Brasileiro de Geografia e Estatística (IBGE) e citado pela Associação Nacional de Auditores Fiscais da Receita Federal (ANFIP), demonstra que a renda média mensal da população $1 \%$ mais rica aumentou aproximadamente 34 vezes em relação ao rendimento da metade da população mais pobre do país. 
não como equilíbrio da sociedade política com a sociedade civil (ou a hegemonia de um grupo social sobre toda a sociedade nacional, exercida através das organizações ditas privadas, como a Igreja, os sindicatos, etc), e é especialmente na sociedade civil que operam os intelectuais.

O conceito estrito de intelectual e de Estado incomodava profundamente Gramsci. Ele percebia que o primeiro conceito - entendido de forma intrínseca - definia o intelectual como aquele que pensa, coordena e gerencia o mundo da produção, da política e da cultura, enquanto os não intelectuais como aqueles que apenas executam as atividades, sobretudo do mundo do trabalho. Angustiava-o também o conceito restrito de Estado, concebido apenas como um conjunto de aparatos político-jurídico-administrativo separado dos aparatos 'privados' da sociedade civil, o que resultava em uma visão dicotomizada acerca das correlações de forças no processo hegemônico.

Para Gramsci (2005), essa dicotomia que perpassa tanto o conceito de intelectual, quanto o de Estado é própria da sociabilidade do capital e se manifesta como um dos entraves para a luta revolucionária. Decerto, o conceito de Estado estrito contribui para a legitimação de uma visão unilateral, presente mormente na classe trabalhadora, que compreende o poder da classe dirigente e dominante centralizado apenas na máquina estatal, negligenciado a sua extensão no âmbito da sociedade civil.

Mas, para Gramsci (2005), o conceito estrito de intelectual é problemático também na medida em que reproduz a ideia de que esse atributo é válido apenas para aqueles que pensam o mundo pela via teórica, técnica e cientificamente, enquanto a maioria pertencente à classe trabalhadora é tida como massa ignorante que deve ser guiada para a reprodução da sociabilidade burguesa.

Nessa perspectiva, Gramsci entende que o intelectual é definido somente pelos atributos intrínsecos da profissão como escrever, pesquisar e criar teorias, o que resulta em uma visão negativa acerca da maioria dos sujeitos que, por não realizarem essa atividade, são desclassificados e vistos como não intelectuais.

Esse prisma que desqualifica a classe trabalhadora, situando-a como incapaz de ser guia de si - que precisa, por sua vez, ser dirigida por outra classe que lhe é estranha - valida um sistema de poder que justifica e reproduz a relação entre dirigentes e dirigidos. Esse poder que subjuga a classe trabalhadora aos que dirigem e dominam sustenta-se na contradição fundamental capital- trabalho.

Assim, os que pertencem à classe hegemônica apropriam-se de parte significativa do acervo material e cultural para se tornarem intelectuais e dirigentes, enquanto a classe produtora da riqueza - que pouco acesso tem ao conhecimento sistematizado - é tida como 
carente de razão, precisando ser tutelada pelos que pensam cientificamente o mundo. Esse é um dos fatores que conduz Gramsci a ampliar o conceito de intelectual, superando a dicotomia entre sábios governantes e ignorantes governados.

Tal ampliação conceitual rompe com a ideia de ignorância como algo natural de uma determinada classe e revela que essa concepção resulta de um longo processo histórico de apassivamento da classe trabalhadora (DIAS, 1996). Assim, a ignorância desvela-se como algo que não é peculiar a determinados grupos sociais, mas produto de um modelo de sociedade que, para se manter, precisa de um sistema que se sustenta na condição de subalternidade, em que os que produzem a riqueza são submetidos ao ordenamento do capital.

A ampliação gramsciana do conceito de intelectual demonstra o elemento de classe que perpassa o processo formativo do ser humano na sociedade burguesa, na qual os filhos da classe trabalhadora têm acesso a um modelo de educação alicerçado em fins imediatos voltados para o mercado de trabalho, enquanto os filhos da classe hegemônica têm outro modelo educativo que os prepara para exercer funções de comando e de domínio na sociabilidade vigente.

Foi ciente dessa relação de subordinação entre dirigentes e dirigidos, que Gramsci (2005) ampliou também o conceito de Estado, compreendendo-o tanto como sociedade política em que predomina a força, como sociedade civil em que prevalece o consenso. $\mathrm{O}$ Estado é, assim, uma unidade dialética de equilíbrio instável entre a dominação das forças subversivas e o consenso de forças aliadas em função da reprodução do ordenamento burguês.

Esse poder que oprime e conquista a fim de instituir o projeto civilizatório da classe dominante e dirigente requer a atividade do intelectual, entendido por Gramsci (2005) como um sujeito histórico que, vinculado aos interesses de classes, assume a tarefa de elaboração e difusão de uma determinada concepção de mundo que contribui para o fortalecimento da identidade de classe que ele representa.

A análise gramsciana sobre o intelectual requer um olhar de dupla dimensão. $\mathrm{Na}$ primeira, o intelectual emerge como um sujeito que exerce uma função articulada a interesses sociais. A atividade intelectual decorre de demandas objetivas de ordem econômica, política e social e requer uma subjetividade que se identifique com os interesses, ideias, valores e crenças da classe que representa, sistematizando-os numa concepção de mundo que é difundida na sociedade.

Esse olhar que articula o intelectual ao conjunto das relações sociais, permite compreendê-lo como um sujeito que desenvolve uma função político-organizativa no ordenamento social em que vive. Assim, o conceito de intelectual é ampliado de tal forma que 
abarca todos aqueles que dispendem de energia psicofísica para desenvolver ações de organização, articulação, direção, transformação ou mesmo de manutenção de uma determinada ordem social.

O pensador sardo defende, assim, que de maneira geral, todo ser humano é intelectual, porque inexiste ação destituída de pensamento. Aquele que age precisa pensar - mesmo que a nível de senso comum - para efetivar o que foi idealizado. Todos pensam e sentem ao fazer algo, o que demonstra a inteireza do gênero humano. Nesse sentido, afirma Gramsci (2014, p. 53, grifo do autor) que não pode haver "[...] atividade humana da qual se possa excluir toda intervenção intelectual, não se pode separar o homo-faber do homo sapiens".

Esse olhar ampliado que capta o sujeito histórico como intelectual sustenta-se no princípio de que "a espécie humana é fundamentalmente uma e, portanto, todos são a um só tempo trabalhador e intelectual" (DEL ROIO, 2018, p. 147). Com base no princípio da omnilateralidade que está diretamente relacionado ao conceito de formação humana - por articular dialeticamente atividade intelectual e manual - Gramsci (2005) estende o conceito de intelectual, abarcando a diversidade que lhe é própria do gênero humano.

Na segunda dimensão do olhar gramsciano, capta-se os intelectuais a partir de critérios intrínsecos que permitem diferenciá-los em graus. Nesse momento, o conceito de intelectual ampliado que considera o humano como ser de pensamento, de vontade e de ação, inclui em si a dimensão da pluralidade que permite compreender a diversidade de sujeitos que exercem de forma profissional a função de intelectual e outros que lidam com a teoria para resolver problemas de ordem mais imediata.

Para Gramsci (2014), ambos são intelectuais, porque ao agir no mundo precisam pensar e efetivar o que foi pensado. No entanto, nem todos os que pensam sobre o pensamento, a ação e a linguagem assumem essa tarefa profissionalmente. Nessa perspectiva, um filósofo e um líder comunitário são intelectuais, porém, se diferenciam na medida em que o primeiro é profissional da atividade crítico-racional, enquanto o segundo não se formou como especialista para exercer essa função socialmente.

Intui-se que o olhar de dimensão ampliada e intrínseca permite compreender o ser humano como intelectual não profissional ${ }^{5}$ e intelectual profissional. Esse entendimento parece que se sustenta no par dialético ser e não ser. Assim, o professor e a professora são intelectuais profissionais, porque ao longo de uma trajetória formativa acumularam

${ }^{5}$ Sobre essa questão, ver o Caderno Carcerário 12 de 1934, no qual Gramsci diz que todos seres humanos podem cozinhar, mas isso não significa que desenvolvam essa atividade profissionalmente. 
conhecimento para assumirem essa função numa dada sociedade. Não são, porém, intelectuais profissionais na medida em que atuam noutra área sem a devida formação.

Desse modo, os que são profissionais em uma determinada área, podem não ser em outras, o que demonstra que Gramsci (2014) compreendeu o movimento dialético entre saber e não-saber contido na filosofia da práxis. Assim, o conceito de intelectual circunscrito apenas aos atributos intrínsecos é superado e emerge outro compreendido como unidade do diverso, porque sintetiza em si mesmo a multiplicidade de sujeitos históricos que assumem a tarefa de sistematização, organização e difusão de ideias, crenças e valores em um determinado modelo de sociedade.

\section{Do intelectual tradicional ao intelectual orgânico do capital}

Com base, então, no binômio unidade-diversidade, Gramsci (2014) entende que o intelectual tradicional é aquele que se origina no bloco histórico feudal e que assumia a tarefa de conectar os servos à elite dominante da época. Assim, são intelectuais tradicionais, padres, advogados, médicos etc - que embora continuem a existir e a assumir funções mais complexas na sociabilidade burguesa - têm sua origem vinculada ao modelo de sociedade precedente ao modo de produção capitalista.

Para Gramsci (2014), esse intelectual é geralmente conquistado pela classe burguesa para contribuir na elaboração, reelaboração e implantação da sua concepção de mundo. Para Del Roio (2018), isso significa que "[...] o capital se utiliza de intelectuais surgidos das entranhas da época feudal [...], esses [...] contribuem muito para a reprodução da ordem, para sua naturalização".

Para Semeraro (2004, p. 71), o intelectual tradicional é o que possui um saber livresco, enciclopédico, postura de superioridade, pouco envolvimento com as questões políticas do seu tempo histórico e que "[...] é incapaz de compreender o sistema da produção e das lutas hegemônicas, onde ferve o jogo determinante do poder econômico e político".

No entanto, esse mesmo intelectual poderá também ser conquistado pelos grupos ${ }^{6} \mathrm{e}$ classes subalternas. Gramsci (2014) reconhece que é preciso que a classe historicamente

\footnotetext{
${ }^{6}$ Pela exposição de Del Roio (2018) compreendemos que, na perspectiva gramsciana, há diferença entre grupos e classes subalternas. O primeiro se refere a parcelas sociais, como intelectuais tradicionais, extratos de comerciantes do ordenamento feudal, artesãos e classes que não construíram a sua própria identidade classista, pois estão profundamente atreladas à lógica dominante. Já a classe subalterna - mesmo que ainda dependente da ideologia burguesa - formada pelos camponeses e operários, demonstra maior organicidade e, precisa organizarse politicamente para congregar todos os grupos subalternos no programa político de superação da sociabilidade do capital.
} 
governada crie os seus próprios intelectuais, mas entende que não é tarefa fácil, porque requer recursos financeiros e longo tempo de formação.

Ciente disso, o autor ressalta que a classe subalterna precisa investir na formação de seus intelectuais. Embora não estejam postas, na sociedade do capital, as condições para a emancipação plena dos indivíduos, é necessário que esse processo formativo tenha como horizonte a formação humana, ao mesmo tempo em que deve conquistar os intelectuais tradicionais que demonstrem identificação com a luta pela emancipação humana.

O intelectual tradicional torna-se, assim, objeto de disputa das classes sociais. Ele pode contribuir tanto para a reprodução da ordem burguesa, quanto para a construção de um programa político que visa a superação da subalternidade, entendida como condição histórica de apassivamento e de negação da autonomia de grupos e classes que são governados pela classe dirigente e dominante.

Como ressalta Marx na obra Ideologia Alemã (1845-1846), as ideias prevalentes num determinado período histórico pertencem à classe dominante. Isso significa que a classe que exerce o poder sobre as demais não domina apenas na estrutura material, pois pretende também, na superestrutura, que a sua concepção de mundo seja incorporada pela classe trabalhadora.

Marx (2007) entende que o poder da classe dominante resulta da articulação dialética entre estrutura e superestrutura. Nesse sentido, a subordinação da classe trabalhadora é expressão tanto do poder econômico, quanto do poder político, social e cultural exercido pela classe dominante.

Na obra supracitada, Marx (2007) instiga-nos a pensar que as ideias dominantes requerem sujeitos que as produzam de modo vinculado a determinados grupos sociais. Noutros termos, as ideias são produzidas e expressam interesses advindos das correlações de forças num determinado contexto sócio-histórico. É nesse sentido, que Gramsci (2016, p. 83) afirma que:

As ideias e as opiniões não 'nascem' espontaneamente no cérebro de cada indivíduo: tiveram um centro de formação, de irradiação, de difusão, de persuasão, houve um grupo de homens ou até mesmo uma individualidade que as elaborou e apresentou na forma política da atualidade.

As ideias, as crenças e valores dominantes são constructos de indivíduos ou de grupos que as elaboraram a fim de difundi-las para serem absorvidas, de forma ativa ou passiva, por um conjunto de sujeitos, constituindo uma determinada visão de mundo. Destarte, o que o sujeito histórico pensa, sente, faz e diz traz marcas das correlações de forças que tecem o 
contexto em que vive. Noutros termos, o pensamento, a linguagem, os afetos e a ação humana expressam, em larga medida, a ideologia hegemônica, entendida como concepção de mundo constituída por um conjunto de princípios, crenças e valores peculiares da classe dirigente e dominante.

Essa condição de classe que, dialeticamente, domina os sublevados e dirige os aliados resultou de um longo processo de construção de poder alicerçado tanto na esfera material, quanto na dimensão superestrutural. Isso significa dizer que o poder que subordina historicamente a classe trabalhadora tem seu fundamento na lógica de extração, acumulação e reprodução da riqueza, e que requer justificação e legitimação para ser reproduzido no plano da superestrutura.

Gramsci (2014) entende que a condição de classe dominante e dirigente constitui-se enquanto tal tanto pela função que ela exerce no mundo da produção, quanto pela prevalência da sua concepção de mundo que foi elaborada e difundida pelos intelectuais orgânicos que assumem a tarefa de conectar governantes e subalternos, estes últimos sendo entendidos como os que não se afirmaram como mestres de si mesmos nas esferas econômica, política, social e cultural.

O intelectual orgânico do capital assume uma função conectiva, pois articula os dominados em razão dos interesses aparentemente universais da classe dominante. Nesse processo de força e convencimento, grupos e classes subalternas identificam-se com o projeto da classe hegemônica, uma vez que são ocultados os interesses antagônicos e defendido o discurso da pseudo liberdade no âmbito individual.

Nesse sentido, o intelectual da classe hegemônica é construtor de vínculo entre governantes e governados. Para tanto, utiliza-se do convencimento para a elaboração do consenso de aliados e da força para o disciplinamento dos sublevados. Essa tática visa formar uma vontade coletiva em sintonia com a concepção de mundo dos que governam, mantendo a maioria dos sujeitos históricos na condição de subalternos.

Dias (1996, p. 34) depreende que a subalternidade não é condição intrínseca, peculiar dos que são dominados e dirigidos historicamente, mas resulta de um sistema de poder que visa apassivar a classe trabalhadora em função da hegemonia burguesa - que é uma "racionalidade de classe que se faz história e que obriga às demais classes a pensar-se nessa história que não é delas" - constituída de teorias e princípios, como também de valores, crenças e paixões.

A racionalidade dominante é elaborada pelos intelectuais orgânicos criados pela classe burguesa para justificar, difundir e reproduzir um modo civilizatório que se sustenta na 
relação contraditória capital-trabalho. Nela, os que compram a força de trabalho produzem os intelectuais para construir e fortalecer a sua identidade de dirigente e dominante e para destruir iniciativas de lutas das classes subalternas que tenham como horizonte a emancipação humana. Para Gramsci (2014, p. 15):

Todo grupo social, nascendo no terreno originário de uma função social no mundo da produção econômica, cria para si, ao mesmo tempo, organicamente, uma ou mais camada de intelectuais que lhe dão homogeneidade e consciência de sua própria função.

Gramsci (2014) articula dialeticamente o surgimento dos intelectuais aos interesses do mundo da produção e às necessidades da construção da identidade de classe. A criação do intelectual vincula-se de forma imediata aos interesses econômico-corporativos da classe que o origina, e ao mesmo tempo, aos interesses políticos, culturais e ideológicos que constituem o projeto hegemônico.

Gramsci (2014) articula estrutura material e superestrutura para compreender a função do intelectual no conjunto das relações sociais. O intelectual orgânico não é um sujeito neutro - como defende o EsP - porque o que ele produz teoricamente expressa, em larga medida, o seu compromisso com a classe a que se vincula.

Assim, atividade do intelectual orgânico da classe burguesa possui dupla função. Ele organiza e difunde a ideologia dominante, mas, concomitantemente, desorganiza os grupos e classes subalternas para que não construam a sua identidade e desistam de lutar coletivamente pela superação da sociabilidade do capital.

O intelectual do capital contribui para legitimação da vontade coletiva hegemônica por meio de um processo que, dialeticamente, une os subalternos em razão do programa político das classes dominantes, mas que os fragmenta em torno de uma proposta alternativa de emancipação humana. A atividade desse intelectual visa ordenar os subalternos em razão de interesses alheios, como também desordená-los para evitar a sua elevação intelectual e moral em marcha para construção da alternativa socialista.

No romance $O$ Leopardo, de Giuseppe Tomasi, que retrata as correlações de forças políticas que culminaram com o processo de unificação da Itália, há um diálogo instigante em que o personagem Tancredi, sobrinho do príncipe Fabrizio Corbera, afirma-lhe: “[...] Se queremos que tudo fique como está, é preciso que tudo mude" (LAMPEDUZA, 2002, p. 42).

Nessa passagem, Fabrizio entende que os movimentos de luta em prol da unificação italiana no século XIX deveriam ocorrer, mas desde que a mudança fosse para fortalecer a 
nobreza. Tudo deve mudar, mas para fazer permanecer o que já está posto. Isso significa que as lutas pela mudança precisam ser absorvidas pela política da classe dominante.

O intelectual orgânico comprometido com a concepção de mundo hegemônica embora num contexto histórico diferente daquele da unificação italiana - parece que caminha na direção da assertiva de Fabrizio. Ele capta os embriões revolucionários das classes subalternas e os aborta por meio da cooptação de suas lideranças e da tática divide et impera (dividir e conquistar) na qual trabalhadores divididos lutam contra si mesmos, contribuindo para a reprodução da sociabilidade dominante.

A atividade desse intelectual visa disciplinar os subalternos para se identificarem com o modo civilizatório do capital. Para tanto, produzem teorias que enobrecem o modus vivendi das classes dominantes e que desqualificam os subalternos como carentes de civilidade.

Fundamentado na lógica dialética que é o processo de interpretação e de intervenção crítica no mundo, Dias (1996, p. 38, grifo nosso) defende que o trabalho do intelectual do poder hegemônico é de dupla dimensão:

As classes trabalhadoras são organizadas por uma lógica e aparelhos (partidos, escolas, etc) que se podem expressar seus interesses imediatos, não podem, contudo, fazê-lo com seus projetos. E não podem porque esses aparelhos e essa lógica foram construídos para realizar outra racionalidade. Assim, as classes trabalhadoras aparecem objetivamente desorganizadas em relação a si mesmas, porque organizadas em relação à racionalidade capitalista.

Dessa forma, reitera-se a dupla função do intelectual orgânico do capital, que pretende organizar a classe trabalhadora de acordo com a hegemonia dominante, e desorganizá-la para não construir um novo projeto hegemônico; uni-la à racionalidade burguesa e desuni-la a fim de fragilizar a consciência de classe; ordená-la de acordo com o disciplinamento vigente e indiscipliná-la para impedi-la de se constituir como vontade coletiva revolucionária.

Ciente desse processo de apassivamento das classes subalternas, Gramsci (2014) propõe a construção de outra racionalidade que precisa ser elaborada a partir do mundo dos subalternos e retornar para eles como ferramenta de luta para conquista da condição de sujeitos históricos, o que demanda a criação de um novo tipo de intelectual orgânico.

\section{O intelectual orgânico da classe subalterna e a função formativa da vontade coletiva revolucionária}

Gramsci (2014) compreende que o intelectual orgânico dos grupos e classes subalternas diferem de forma significativa daquele que representa os interesses das classes 
dominantes. O primeiro pretende colaborar na construção da teoria revolucionária que desvela as contradições do sistema hegemônico e organiza a luta política para superação da dominação. O segundo defende a manutenção da ordem vigente e, para tanto, a produção e difusão de ideias que visam a absorção de sujeitos e grupos em prol da pequena política das classes hegemônicas.

Para Semeraro (2004, p. 76-77), os intelectuais das classes subalternas "tornam-se orgânicos ao projeto dos subjugados quando consideram eles como sujeitos não como objeto. Seu compromisso não é com as eleições [...], a manutenção de poder de políticos", mas com a elevação intelectual e moral dos governados a fim de construírem um novo projeto civilizatório que requer a superação da contradição capital-trabalho.

A tarefa de conservação do sistema de dominação não é do intelectual das classes governadas, mas daqueles que são “[...] funcionários dos grupos dominantes, incapazes de [...] uma autocrítica da classe no poder [...], se colocam à serviço da máquina para lubrificar as suas engrenagens e obter interesses corporativos" (SEMERARO, 2004, p. 75).

O intelectual da subalternidade, diferente daquele das classes governantes, não ignora o saber de senso comum que é fragmentário e ocasional, porque o tem como ponto de partida para a construção de uma nova concepção filosófica do mundo, que explica de forma sistemática e coerente as razões da condição dos subalternos, visando entusiasmá-los e organizá-los para a construção de uma nova racionalidade que pretende fazer-se história (DIAS, 1996).

Numa edição do jornal proletário L'Ordine Nuovo, de 15 de maio de 1919, no qual Gramsci era o secretário de redação, demonstra que a luta revolucionária implica unidade dialética entre teoria, vontade e organização disciplinada ${ }^{7}$ das classes subalternas. A luta dos subalternos não pode ser realizada no desespero, de forma intempestiva e indisciplinada, porque requer imperativos próprios de si mesma, reconhecidos pelo pensador sardo: "Instruívos, porque teremos a necessidade de toda vossa inteligência. Agitai-vos, porque teremos necessidade de todo o nosso entusiasmo. Organizai-vos, porque teremos necessidade de toda a nossa força".

A revolução não é um processo espontaneísta, irracionalista, voluntarista e imediatista, mas um processo que implica estudo para apropriação da teoria revolucionária, pois sem ela perde-se a leitura crítica da historicidade do real, das correlações de força econômica, política,

\footnotetext{
7 Disciplinar não significa negar o poder de iniciativa das classes subalternas. Pelo contrário, significa a necessidade de organização da luta revolucionária sustentada num conjunto de princípios, normas e valores que oriente os sujeitos subalternos para o comprometimento com o horizonte da emancipação humana.
} 
social e cultural, das contradições da lógica do capital e das táticas de cooptação de lideranças e liderados.

O elemento 'espontaneidade' não é suficiente para a luta revolucionária: ele jamais leva a classe operária a superar os limites da democracia burguesa existente. É necessário o elemento 'consciência', o elemento 'ideológico', ou seja, a compreensão das condições em que se luta, das relações sociais em que o operário vive, das tendências fundamentais que operam no sistema dessas relações, do processo de desenvolvimento que a sociedade sofre pela existência em seu seio de antagonismos inelimináveis [...] (GRAMSCI, 2004, p. 294).

Revolução sem teoria revolucionária resulta em rendição à racionalidade dominante. Os que lutam contra a classe que os torna subalternos não podem interpretar e intervir no mundo de acordo com o intelecto político de quem os domina. Precisam apropriar-se de forma teórica, técnica e científica de uma nova teoria para se contraporem e superarem a hegemonia dominante.

Para Gramsci (1999), a teoria é um elemento indispensável na luta revolucionária, mas que demanda um processo catártico em que as ideias que fundamentam o agir dos subalternos precisam se transformar também em força volitiva. Noutras palavras, o pensamento revolucionário precisa conquistar, envolver, entusiasmar e convencer conscientemente os subalternos para formarem uma vontade coletiva em prol da luta pela liberdade humana. Essa tarefa exige a articulação indissociável entre o pensamento que pensa e intervém no mundo e a paixão que encanta os que pretendem superar a condição de subalternidade, como bem retrata Coutinho (2018, p. 123):

O movimento revolucionário dos trabalhadores reclama, para levar adiante a construção do socialismo, uma teoria da ação transformadora [...], mas também uma linguagem capaz de articular essa consciência ao sentir das massas. Pois é sob uma forma dramática, simbólica, afetiva que o saber se torna vontade coletiva.

A revolução dos subalternos fundamenta-se na filosofia da práxis, na vontade revolucionária e na organização política. Toda a multiplicidade de forças dos subalternos precisa ser organizada conforme o horizonte da emancipação humana, pois, caso contrário, permanecerá disciplinada por forças opostas à elevação intelectual e moral do ser humano.

É imensa a tarefa do intelectual da hegemonia em devir, pois ele precisa conhecer as paixões manipuladas das classes subalternas, a luta dela para se manter viva, o seu quadro axiológico, a percepção que tem de si mesma e do poder dominante, a visão fatalista e/ou otimista de mundo, a crença na concepção de Estado positivo, o discurso legitimador da 
fragmentação entre estrutura material e superestrutura, as correlações de forças, o processo histórico de constituição da sociabilidade do capital, a crença ingênua na democracia burguesa, dentre outros.

Esse conjunto de questões precisa ser desmistificado pelo intelectual orgânico comprometido com a emancipação humana. Nesse sentido, sua atividade intelectual pressupõe a capacidade de sentir o mundo dos subalternos e, ao mesmo tempo, refletir racionalmente para transformar o desespero, a dor de ser subjugado e as alegrias pelas conquistas obtidas em pensamento filosófico e científico que se transforma num novo senso comum mobilizador e organizador do Estado ético-político ${ }^{8}$ (GRAMSCI, 2016).

Para o pensador italiano, o intelectual orgânico dos 'simples' sente o drama da existência subjugada deles e elabora uma teoria que permite a crítica radial à lógica hegemônica, visando construir um novo ordenamento social alternativo. A luta requer a organização dos intelectuais num partido ${ }^{9}$ comprometido com a emancipação humana e a unidade deles com os subalternos.

\section{Considerações finais}

A atividade do intelectual comprometido com a elevação intelectual e moral dos subalternos tem também dupla função. Ele precisa criticar e fragilizar a racionalidade dominante, para superá-la, em razão da consolidação de uma nova hegemonia dos subalternos.

Depreende-se que, para Gramsci (2004), o trabalho é de desagregação da lógica burguesa e, ao mesmo tempo, de construção de alianças com os subalternos a fim de construir e fortalecer a racionalidade emancipadora que pode ser desenvolvida nos mais diversos aparatos 'privados' de hegemonia, como sindicatos, associação de moradores, centros de formação de jovens e adultos, movimentos de bairros e favelas, movimentos do campo, grupo de jovens, movimento de mulheres, dentre outros.

É preciso superar a indiferença e agir, mas não de forma espontaneísta e carente de teoria revolucionária. A organização dos subalternos não se faz com amadorismo, pois pressupõe a criação de táticas desintegradoras da lógica hegemônica e que visem integrar as forças embrionárias de caráter revolucionário dos subalternos.

${ }^{8}$ Devido à censura carcerária, Gramsci utiliza esse conceito para se referir ao socialismo

${ }^{9}$ Pelo limite de espaço, esse conceito não será aprofundado neste trabalho. Mas, vale ressaltar que o partido é compreendido por Gramsci como intelectual coletivo, pois ele é a unidade de cérebros que, em comunhão com os subalternos, elaboram o programa político da emancipação humana. 
Seria ilusão pretender lutar, em parceria com os 'simples', fundamentado nas mesmas teorias que validam a sua condição de subalternidade. O intelectual orgânico que educa contra e para além da sociabilidade do capital e que tem como horizonte a formação humana (MÉSZAROS, 2011), defende a filosofia da práxis como teoria dos subalternos, contrapõe-se ao reformismo e ao discurso de conciliação de classes, explicita a contradição fundamental entre capital e trabalho, relaciona estrutura e superestrutura na análise do real, produz conhecimento filosófico-científico e contribui na organização da luta contra o processo de desumanização do sujeito histórico.

Esse intelectual atua na contramão do EsP, que é um dos programas da extrema direita brasileira. Esse movimento, reúne intelectuais de baixo grau de conhecimento e de humanidade que pretendem anular mesmo as conquistas parciais obtidas pelos subalternos na sociabilidade burguesa. Além disso, disseminam o discurso de ódio contra os subalternos.

No cenário da crise estrutural do capital, intensificada pela pandemia da COVID-19, os grupos e classes governadas vivem uma situação de extremo desespero, marcada pelo subemprego, desemprego, alta taxa de contaminação e alto índice de letalidade. Conforme os dados do consórcio de imprensa publicados no dia 06 de outubro de 2020, o Brasil chegou a 147.571 (centro e quarenta e sete mil, quinhentos e setenta e um) óbitos provocados pela Covid-19.

Diante desse quadro desastroso e da indiferença do presidente da república e dos seus aliados, os intelectuais orgânicos dos subalternos não podem silenciar. A tarefa urgente requer denúncia do abandono pela vida dos subjugados, envolvimento em movimentos de solidariedade que visam contribuir com pessoas acometidas pela COVID-19, criação de uma unidade política disciplinada contra as forças do capital, realização de atividades formativas sobre a teoria revolucionária e defesa intransigente da emancipação humana. Esse desafio é imenso, mas a luta deve continuar mesmo nos momentos catastróficos da vida.

\section{REFERÊNCIAS}

BRASIL. Câmara dos Deputados. Projeto de Lei n. 867, de 23 de março de 2015. Inclui, entre as diretrizes e bases da educação nacional, o "Programa Escola sem Partido". Brasília, DF, 2015. Disponível em:

https://www.camara.leg.br/proposicoesWeb/fichadetramitacao?idProposicao=1050668. Acesso em: 1 jul. 2020.

BRASIL. Sistema Único de Saúde (SUS). Painel Coronavírus. Disponível em: https://covid.saude.gov.br/. Acesso em: 2 ago. 2020. 
COUTINHO, E. G. Mito e hegemonia: a paixão segundo Antônio Gramsci ou Gramsci e Sorel: a tradução realista do conceito de mito. In: SCHLESENER, A. H.; OLIVEIRA, A. L.; ALMEIDA, T. M. G. (Org.). A atualidade da filosofia da práxis e políticas educacionais. Curitiba: UTP, 2018. p. 87-126.

DEL ROIO, M. Gramsci e a emancipação dos subalternos. São Paulo: Editora Unesp, 2018.

DIAS, Edmundo. Hegemonia: racionalidade que se faz história. In: DIAS, E. H. et al. O outro Gramsci. São Paulo: Xamã, 1996.

GRAMSCI, A. Caderno do Cárcere. Maquiavel. Notas sobre o Estado e a Política. Trad. Carlos Nelson Coutinho. 7. ed. Rio de Janeiro: Civilização Brasileira, 2016. V. 3.

GRAMSCI, A. Caderno do Cárcere. Os Intelectuais. O Princípio educativo. Jornalismo. Trad. Carlos Nelson Coutinho. 7. ed. Rio de Janeiro: Civilização Brasileira, 2014. V, 2.

GRAMSCI, A. Cadernos do Cárcere. Introdução ao estudo de filosofia de Benedetto Croce. Trad. Carlos Nélson Coutinho. Rio de Janeiro: Civilização Brasileira, 1999. v. 1.

GRAMSCI, A. Cartas do Cárcere. Trad. Luiz Sérgio Henriques. Rio de Janeiro: Civilização Brasileira, 2005.v, 2.

GRAMSCI, A. Escritos políticos (1921-1926). Trad. Carlos Nelson Coutinho. Rio de Janeiro: Civilização Brasileira, 2004. v. 2.

LAMPEDUSA, G. T. O Leopardo. Tradução Leonardo Cadignoto. São Paulo: Nova Cultural, 2002.

MARX, K. A ideologia alemã: crítica da mais recente filosofia alemã em seus representantes Feuerbach, B. Bauer e Stirner, e do socialismo alemão em seus diferentes profetas. São Paulo: Boitempo, 2007.

MÉSZÁROS, I. Para além do capital: rumo a uma teoria de transição. Tradução Paulo Cezar Castanheira, Sérgio Lessa. São Paulo: Boitempo, 2011.

SEMERARO, G. (Org.). Filosofia e política na formação do educador. Aparecida, SP: Ideias \& Letras, 2004. 


\section{Como referenciar este artigo}

SANTOS, P. P.; SANTOS, E.; OLIVEIRA, D. K. L. O intelectual orgânico e a construção da vontade coletiva da classe subalterna na direção da formação humana. Revista on line de Política e Gestão Educacional, Araraquara, v. 24, n. 3, p. 1598-1614, set./dez. 2020. eISSN:1519-9029. DOI: https://doi.org/10.22633/rpge.v24i3.14295

Submetido em: 30/06/2020

Revisões requeridas: 20/07/2020

Aprovado em:26/08/2020

Publicado em: 01/09/2020 